\title{
Retraction Note: Paediatric Ewing-like sarcoma arising from the cranium - a unique diagnostic challenge
}

\author{
Ian J. Robertson ${ }^{1 *}$, Fadel Bennani ${ }^{2}$, Ronan S. Ryan ${ }^{3}$, Waqar Khan ${ }^{1}$ and M. Kevin Barry ${ }^{1,4}$
}

\section{Retraction Note}

This article [1] has been retracted by the authors because, contrary to the statement in the article, they did not obtain the necessary written informed consent from the patient's parents to publish this case. The article is no longer available online in order to protect the patient's privacy. The authors have agreed to the retraction.

\footnotetext{
Author details

${ }^{1}$ Department of Surgery, Mayo General Hospital, Castlebar, Co Mayo, Ireland.

2Department of Histopathology, Mayo General Hospital, Castlebar, Co Mayo, Ireland. ${ }^{3}$ Department of Diagnostic Radiology, Mayo General Hospital, Castlebar, Co Mayo, Ireland. ${ }^{4}$ Professor of Surgery, National University of Ireland, Galway (NUIG), Galway, Ireland.
}

Received: 19 September 2016 Accepted: 19 September 2016

Published online: 11 October 2016

\section{Reference}

1. Robertson IJ, Bennani F, Ryan RS, Khan W, Barry MK. Paediatric Ewing-like sarcoma arising from the cranium - a unique diagnostic challenge. Diagn Pathol. 2016;11:54.

\footnotetext{
* Correspondence: irobertson@me.com

'Department of Surgery, Mayo General Hospital, Castlebar, Co Mayo, Ireland
} 